\title{
EXAMINING THE STRUCTURED USES OF CONCEPTS AS TOOLS: CONVERGING INSIGHTS
}

\begin{abstract}
Examining the historical development of scientific concepts is important for understanding the structured routines within which these concepts are currently used as goal-directed tools in experiments. To illustrate this, I outline how the concepts of mental imagery and hallucinations each draw on an older interdependent set of associations that, although nominally discarded, continues to structure their current independent uses for pursuing discrete experimental goals. In doing so, I highlight how three strands of literature offer mutually instructive insights into how the uses of current scientific concepts contribute to experimental practices. The first strand of literature includes recent scholarship examining how the uses of scientific concepts can enable scientific practices (e.g., Boon 2012, Brigandt 2012, Feest 2010, Steinle 2012), the second strand comes from the technoscientific studies focused on non-human agency (Pickering 1995), and the third draws attention to how the functions of concepts are grounded by the set of historically contingent experimental practices (e.g., Canguilhem 2008, Tiles 1984).
\end{abstract}

Keywords: concepts-as-used, experimental practice, neuroscience, philosophy of science as practiced, history and philosophy of science, science and technology studies

Examining the historical development of scientific concepts offers a step towards understanding the structured routines within which these concepts are currently used as goal-directed tools in experiments. This claim draws on three strands of scholarship that converge within the broader fields of history, philosophy, and social studies of the sciences. Each strand offers different insights into how the uses of scientific concepts contribute to experimental practices.

To illustrate the value of building on the convergence of these accounts of scientific practice, I will outline how they can be brought together to help un-

* School of Historical and Philosophical Studies, Faculty of Arts, University of Melbourne, Parkville, VIC 3010, Australia, eden.smith@unimelb.edu.au, ORCID: https://orcid.org/ oooo-0003-4058-6619. 
derstand a tension I identify between past and present uses of the concepts of mental imagery and hallucination. To this end, I will discuss a series of examples where implicit associations between these historically interdependent concepts can be seen in the structured routines of the current independent goal-directed uses of these concepts during neuroimaging experiments.

\section{HIGHLIGHTING THE CONVERGENCE OF THREE STRANDS OF RESEARCH}

The first strand of research I appeal to includes a range of philosophical examinations into how the uses of scientific concepts enable scientific practices. In this context, scientific concepts have been described as contributing to empirical knowledge in ways that extend beyond their traditionally recognized roles in mental and linguistic representation. ${ }^{1}$ This type of approach highlights the multiple uses for scientific concepts in practice: from mediating the interplay between theoretical and experimental practices (Feest 2012, Bloch 2012a) to contributing to experimental research in ways that are not determined by the theoretical frameworks within which the concepts may also be embedded (Arabatzis 2012). Concepts are shown to be used in theoretically polyvalent ways (Arabatzis, Nersessian 2015, Schmidgen 2014), as useful even when they fail to pick out natural kinds (Bloch 2012b, Waters 2014), and as patchwork arrangements that, having unfolded over generations of historically contingent uses, can resist individual intentions (Kindi 2012, Nersessian 2012).

This interest in scientific practice has supported detailed accounts of concepts being used as investigative tools (Feest 2010, Bloch 2012a), ${ }^{2}$ as well as accounts that highlight the ways in which concepts are used for pursing specific epistemic goals (Brigandt 2010, Steinle 2010).3 Leaving aside important

\footnotetext{
${ }^{1}$ Although outside the present scope, debates also continue around questions of how general concepts function as mental and linguistic representations, particularly within the history and philosophy of psychology (cf. Bloch-Mullins 2015, Machery 2007).

${ }^{2}$ In this context, tools are devices that, whether physical or not, "enable us to do something" in ways that generate data - and therefore knowledge - within scientific practice (Feest 2010: 180-181).

3 I am following others in using the term "epistemic goal" for those goals that pertain to generating knowledge (Brigandt 2012: 78, Steinle 2012: 107, MacLeod 2012: 68). Within this context, epistemic goals may be specific to a discipline (such as the goal of explaining cell-cell interaction in cell-biology as Brigandt describes) or they may be specific to the given collection of phenomena investigated (such as the goal of finding a regularity that predicts the behaviour of a type of phenomena across multiple disciplines).
} 
differences, this strand of the philosophical literature highlights that concepts are more than mental or linguistic representations: they can be used as theoretically polyvalent investigative tools for pursing specific epistemic goals.

Disconnected from these recent explorations of the uses of concepts is a second strand of scholarship that contributes most directly to studies of scientific and technological practices. Its focus is on the ways material instruments can produce effects on the world that are outside the control of human intention (Haraway 2006, Ihde 2009, Latour 2005, Law, Mol 2008, Robins 2008). Within this context, Andrew Pickering and Adam Stephanides (1992) offer a tantalizing link between these accounts of material and various accounts of conceptual practices.

Along with others in this area of scholarship, Pickering (1995) argues that scientific knowledge emerges through the interactions between human agency (intentional actions) and material agency (such as non-intentional material resistances to human intentions). Building on this view of human-material interactions, Pickering (1995: 115) further argues that systems of concepts, as conceptual structures, can embody what he calls "disciplinary agency" - that is, the agency of disciplined human performances that carry routine conceptual associations that hang together to "carry human conceptual practices along, as it were, independently of individual wishes and intents." Routinized in this way, conceptual structures can act in an analogous way to the routinized participation of machines in experiments (Pickering 1995: 29, 70). For example, by embodying systematic "machine-like actions," concept uses carry routinized associations into experimental practices (Pickering 1995: 142-144). Within individual experiments, these disciplined systems of conceptual associations can then contribute to the production of scientific knowledge by framing machinic performances (Pickering 2006, 2015). Positioned within the context of studies of material instruments and conceptual practice more broadly, Pickering's approach suggests that there are disciplined routines of using systems of concepts in ways that can contribute to investigative practice in analogous ways to that of the routinized participation of machines in experiments (Smith 2018a: 20-41).

The third strand of scholarship, intersecting with the other two, are historical accounts of the contingent and heterogeneous elements of dynamic scientific practices (Chang 2014, Pickering 2012, Steinle 2016, Rheinberger 2009). 4 Two scholars who helped to forge this historically informed approach to the philosophy of scientific practice were Gaston Bachelard and Georges

\footnotetext{
4 While highlighting the contingent dynamics within which human, material, and conceptual elements of experimental practices interact, these approaches share an underlying appreciation of the robust scientific knowledge that contingent practices can generate.
} 
Canguilhem. Bachelard argues that it is only by examining the route which led to the dynamic and "public life" of current concepts that the historical accretions entrenched in these terms can be realized (Tiles 1984: 157-159). This insistence that a concept has a dynamic and historically contingent "public life" stems from a view of concepts as being used by communities as they engage in experimental practices (not just as elements of theories) such that the uses of a concept are subject to the resistance of the material world (rather than as determined by the relevant linguistic frameworks) (Tiles 1984: 153). This notion of resistance (from the material world) draws attention to the mutual instructions that can form between phenomena, instruments, concepts, and experimental methods (Rheinberger 2009, 2010).

The dynamics between these mutually instructing aspects of scientific practice emerge and change over time. For example, Bachelard emphasizes that concepts carry remnants of their past through assumptions, conceptual associations, and perceptual habits that can only be understood within the broader (social and material) context of the historical development of a given concept (Gutting 1989: 17). Similarly, Canguilhem (2008: 9, 43, 76) describes the functions of concepts as grounded by the sets of historically contingent experimental practices they are used within. In doing so, Canguilhem offers a view of scientific concepts as complex and dynamic "laboratory actors" that combine terms, definitions, and phenomena and interact with material devices (Schmidgen 2014: 234, 254).

Although maintaining significant differences, drawing these three strands of scholarship together demonstrates the value of examining the uses of scientific concepts from multiple perspectives. I use each of these strands to highlight a specific element of scientific practice: uses of scientific concepts as tools for specific goals, the dynamic interactions between conceptual, material, and human participants in experiments, and the continued relevance of the historical contexts within which current concepts emerged.

To illustrate the value of this convergence, I will briefly outline an example of the potential it offers for understanding how specific concepts are used in practice. In doing so, I seek to highlight how scientific concepts can be used as taken-for-granted tools that function within networks of routine associations. In particular, I aim to emphasize that these associations are grounded by historically contingent dynamics that structure how specific concepts are used (in concert with human and material participants) within scientific practices. 


\section{COMPARING THE CONCEPTS OF MENTAL IMAGERY AND HALLUCINATIONS}

This example is drawn from a larger project that involved a comparative analysis of the concepts of mental imagery and hallucination as used in documented neuroimaging experiments. 5 Both concepts are used in neuroimaging experiments for individuating specific types of sensory-like mental phenomena, which I'll refer to as SLMP for short. As an analytic category, SLMP include any wakeful endogenous sensation that occurs in the absence of relevant perceptual stimuli. For example, visual SLMP are experienced, to varying degrees, "as if" seen, auditory SLMP are experienced "as if" heard, and so on for taste, smell, and the other sensory modalities. When it comes to neuroimaging experiments, the concept of mental imagery is used to individuate those SLMP that merely resemble perception, while the concept of hallucinations is used for individuating those SLMP that have a compelling sense of perception.

While this difference in the degree of perceptual similarity is often taken for granted, it turns out that attempts to differentiate between those SLMP that merely resemble perception and those with a compelling sense of perception were never adequately resolved (Smith 2018b). Instead, contrasting sets of typical characteristics became associated with mental imagery and hallucinations, respectively, that carried along entrenched expectations about an idealized distinction between ordinary and pathological SLMP (cf. Table 1).

\begin{tabular}{lll}
\hline & \multicolumn{1}{c}{ MENTAL IMAGERY } & \multicolumn{1}{c}{ HALLUCINATIONS } \\
\hline Perceptual Similarity & Variable vividness of SLMP & Abnormally vivid SLMP \\
& Fleeting SLMP & Concrete SLMP \\
& Tentative SLMP & Palpable SLMP \\
\multirow{3}{*}{ Reported location } & Internally located & Externally located \\
& Not within perceptual space & Within perceptual space \\
Volition and Control & Effortfully generate SLMP & Spontaneous SLMP \\
& Manipulable SLMP & Obstinate SLMP \\
& Dismissible SLMP & Absorbing SLMP \\
Attribution of Source & Self-attributed & Not self-attributed
\end{tabular}

5 The details of this comparative analysis are included in my dissertation (Smith 2018a). Here, I focus on exploring one of the research intersections that I drew upon as part of that project. 


\begin{tabular}{lll} 
Level of Insight & $\begin{array}{l}\text { Insight maintained: } \\
\text { recognition that SLMP are } \\
\text { not perceptions }\end{array}$ & $\begin{array}{l}\text { Lack of insight: } \\
\text { belief that the SLMP are } \\
\text { perceptions }\end{array}$ \\
\hline
\end{tabular}

Table 1. Inverse characteristics typically associated with either mental imagery or hallucinations

As this table highlights, there was an inverse relationship between the sets of characteristics typical of each concept: hallucinations can be characterized as what mental images are not, and vice versa. The causal relevance of the inverse characterization of two discrete types of SLMP remains disputed. Nonetheless, these inverse characterizations enabled the concepts of mental imagery and hallucinations to each be used as a tool for individuating specific instances of SLMP for further investigation.

The relevance of the characteristics for the uses of these two concepts as tools can be illustrated by drawing attention to a puzzle that emerges from comparing the respective uses of these concepts in neuroimaging experiments. The first piece of this puzzle is that reported findings (of correlations between SLMP experiences and localized changes in neural activity) are similar regardless of whether the concept of mental imagery or hallucinations was used to individuate the instance of the type of SLMP being investigated (Allen et al. 2008, Hill, Linden 2013: 34-35).

This overlap in findings is not surprising: recognized in meta-analyses and literature reviews, it is usually explained as indicating that there is some low-level sensory processing common to all SLMP. The expectation remains that additional, as yet unidentified, top-down regulatory mechanism will eventually explain the difference between the mere resemblance to perception of mental imagery and the dangerously perception-like hallucinations.

An overlap in the reported findings by experiments using the concept of either mental imagery or hallucinations is therefore not a problem in and of itself. ${ }^{6}$ Rather, the problem with the overlap emerges when the concepts of mental imagery and hallucinations are used independently of each other despite unresolved uncertainty about which of the processes are unique to either. By avoiding the uncertainty around these similarities (and the problems

${ }^{6}$ For example, implicating similarly localized activity in the explanatory mechanisms of two distinct mental phenomena may reflect genuine differences (macroanatomical regions are well-known to contribute to multiple neurocognitive functions and there can also be multiple networks of activity that incorporate overlapping regions during different mental phenomena). 
this uncertainty presents for independent uses of each concept), the focus can remain on developing neurophysiological explanations unique to just one of these conceptualizations of SLMP. For example, the similarities are explained away rather than investigated: presented as merely minor overlapping elements within two distinct neurophysiological processes (Badcock, Hugdahl 2012, Grossberg 2002, Shine et al. 2015).

These expected overlaps were evident in a comparative analysis of studies using the concepts of either mental imagery or hallucination (Smith 2018a): equivalent correlations between a given type of SLMP and a specific brain region were routinely reported regardless of whether the SLMP investigated were conceptualized as mental imagery or hallucinations. More surprisingly, this comparison also highlighted that such similar findings were never recognized as such at the time. Instead, findings of SLMP-correlated changes in neural activity were always reported as uniquely relevant to understanding either the functions of mental imagery or the dysfunction responsible for hallucinations.

This lack of recognition is highlighted by the published accounts' of these experiments failing to discuss the possibility that their findings might relate to low-level processes shared by all SLMP. Instead, findings of equivalent neural activity in any given brain region were always presented as supporting divergent knowledge claims about the role of that region in the neurocognitive processes proposed to underlie either mental imagery or hallucinations. For example, the inferior frontal gyrus was argued to both demonstrate the functional overlap between language processes and auditory mental imagery, and demonstrate the role of language processing in underlying or reinforcing the pathophysiology of auditory hallucinations (e.g., Diederen et al. 2010, Hoffman et al. 2007, Rudner, Rönnberg, Hugdahl 2005).

One explanation for these diverging claims could be that the equivalent experimental findings were simply interpreted differently. However, while certainly part of the story, this does not offer a complete explanation. I have argued that, in addition to this, the concepts of mental imagery and hallucination were each used in the design and implementation of experimental methods (Smith 2018a).

In this broader project, the accounts of scientific practice mentioned above each contributed to my understanding of the uses of the concepts of mental imagery and hallucination in documented experiments. Firstly, I explored how each concept functioned as a tool taken-for-granted in its use for individuating a given type of SLMP during the design and implementation of these experiments (an account that can be developed by drawing on the concepts-as-used literature mentioned earlier). Secondly, focusing on their func- 
tions as taken-for-granted tools, I examined how these concepts each carried along entrenched associations about distinctions between functional and dysfunctional SLMP (highlighting the need to understand the historical contexts of concepts that Bachelard, Canguilhem, and others call for). Thirdly, I argued that these associations were implicitly carried along by the routinized uses of each concept in ways that interact with human and material elements of experimental practices (a dynamic that can be understood by drawing on the work on human-nonhuman interactions mentioned earlier).

To offer another example, the paradigmatic conditions for measuring the neuroanatomical correlates of SLMP were always dependent on the concept used to individuate the SLMP of interest. This can be illustrated by the way that the inverse sets of routinized associations (Table 2) were evident in the instructions given to subjects.

\begin{tabular}{llll}
\hline & MENTAL IMAGERY & HALLUCINATIONS & $\begin{array}{l}\text { ROLE OF CHARACTERISTICS IN } \\
\text { MEDIATOR-VIEW OF SLMP }\end{array}$ \\
\hline $\begin{array}{l}\text { Perceptual } \\
\text { Similarity }\end{array}$ & $\begin{array}{l}\text { Low similarity to } \\
\text { perception }\end{array}$ & $\begin{array}{l}\text { High similarity to } \\
\text { perception }\end{array}$ & $\begin{array}{l}\text { Explains why SLMP are (or } \\
\text { are not) able to be regulated } \\
\text { by reasoned judgement }\end{array}$ \\
$\begin{array}{l}\text { Reported } \\
\text { Location }\end{array}$ & Internally located & Externally located & \\
$\begin{array}{l}\text { Volition } \\
\text { and Control }\end{array}$ & $\begin{array}{l}\text { Voluntary and/or } \\
\text { Controlled }\end{array}$ & $\begin{array}{l}\text { Involuntary and } \\
\text { Uttribution } \\
\text { of Source }\end{array}$ & Self-attribution \\
$\begin{array}{l}\text { Level of } \\
\text { Insight }\end{array}$ & Insight maintained & Other-attribution \\
\hline
\end{tabular}

Table 2. Characterising concepts in the context of mediator-views of SLMP

For instance, when scanning for mental imagery, subjects were given detailed instructions on how to act. No justifications were offered for the routine inference that voluntary or manipulatable SLMP would be required for these actions. In the few cases where self-reported characteristics of SLMP were documented, they merely provided post-hoc justifications for the act requested. In contrast, when scanning for hallucinations, subjects were instructed to be passive: only to indicate the presence or absence of hallucinations. Any inclusion of self-reports in experiments investigating hallucinations were secondary and very carefully justified. Furthermore, when these self-reports of hallucinations failed to match up with expectations, they were casually disregarded. 
Across multiple such examples, these concepts could each be understood as a tool used for pursuing specific goals, a tool that carried historically contingent routine associations that interacted with human and material elements of practice to intervene throughout the experimental design and implementation. For example, the goal of the experiments using the concept of mental imagery was always to understand the role of ordinary SLMP in neurocognition (and how this might go awry). Whereas, when investigating hallucinations, the goal was always to investigate dysfunctional neurocognitive processes.

At first pass, it is reasonable to expect that these differing goals simply reflect a disciplinary divide (between, say, psychology and psychiatry). However, disciplinary divides cannot fully account for what I found. Far from being discipline specific, the difference between the goals each concept was used to pursue remained consistent across multiple variables: across several disciplinary contexts, within shared publication constraints and methodological techniques, and for pursuing diverse experimental aims. A disciplinelevel explanation would also obscure that these goals were theory-polyvalent and specific to experimental practices. Indeed, broadening the contexts to include clinical practices reveals the ongoing difficulties in characterizing discrete types of SLMP: depending on context, mental images are considered both normal and clinically relevant. Likewise, hallucinations emerge as both a key symptom of clinically relevant pathologies and are recognized as common within the non-clinical populations (cf. Tables 3 and 4).

\begin{tabular}{llll}
\hline & \multicolumn{1}{c}{ TyPICAL } & SPONTANEOUS & \multicolumn{1}{c}{ INTRUSIVE } \\
& MENTAL IMAGERY & MENTAL IMAGERY & MENTAL IMAGERY \\
\hline Perceptual Similarity & Variable & Variable & High \\
Location & Internal & Internal & Internal \\
Volition & Voluntary & Involuntary & Involuntary \\
Control & Manipulable & Manipulable & Uncontrolled \\
Duration & Fleeting & Variable & Extended \\
Attribution & Self & Self & Self \\
Insight & Maintained & Maintained & Maintained \\
Subjective Value & Positive & Positive & Negative \\
Emotional-valence & Benign & Benign & Disruptive \\
Content & Useful & Variable & Unwanted \\
Frequency & Variable & Frequent & Frequent \\
\hline
\end{tabular}

Table 3. Adapted characterisations of mental imagery 


\begin{tabular}{llll}
\hline & \multicolumn{1}{c}{ TyPICAL } & CliniCALLY RELEVANT & Non-PATHOLOGICAL \\
& HALLUCINATIONS & \multicolumn{1}{c}{ HALLUCINATIONS } & \multicolumn{1}{c}{ HALLUCINATIONS } \\
\hline Perceptual Similarity & High & not specified & not specified \\
Location & External & Variable & Variable \\
Volition & Involuntary & Involuntary & Involuntary \\
Control & Uncontrolled & Uncontrolled & Uncontrolled \\
Duration & Persistent & Extended & Fleeting \\
Attribution & Others & Variable & Variable \\
Insight & Lacking & Variable & Variable \\
Subjective Value & Negative & Negative & Variable \\
Emotional-valence & Disruptive & Disruptive & Benign \\
Content & not specified & Unwanted & Variable \\
Frequency & Frequent & Frequent & Variable \\
\hline
\end{tabular}

Table 4. Adapted characterisations of hallucinations

Rather than being tied to the dynamics of either a theoretical context or a given discipline, I propose that these discrete goals can be better understood as components of each concept by drawing on the strands of literature mentioned earlier. In this context, the concepts of mental imagery and hallucination can each be understood in the following ways: as (a) independent tools used for pursing discrete goals; as (b) carrying along entrenched routines that structure their contribution to the dynamic human-nonhuman interactions within localized experimental practices towards these goals; and as (c) contingent upon the shared historical conditions within which these two concepts came to be used independently of the other for pursing these goals.

More simply, the documented uses of these two concepts in neuroimaging experiments can be understood in relation to the historical contexts within which the uses of these interdependent concepts came to be structured as an independent tool for investigating these specific goals. The details of the intersection between the histories of these concepts are available elsewhere (Smith 2018a, b). For the present purposes, I will highlight just two points. The first point is that a shared philosophical view of SLMP pre-dates both concepts. Within philosophy, SLMP have predominantly been positioned as mediating between perception and thought by serving memory and imagination - a mediating role that needed to be carefully regulated to avoid confusing thoughts with perception. ${ }^{7}$ Within this context, the same set of inverse

7 Note that this philosophical tradition includes diverse views that are beyond the present 
characteristics outlined in Table 1 helped to explain when and why some experiences of SLMP are necessary while other SLMP experiences are dangerous (Table 2).

During the $19^{\text {th }}$ century, these same inverse characteristics helped to differentiate between mental imagery and hallucinations. Along the way, the concept of mental imagery came to be used for investigating those SLMP that were positioned as required for experiencing memories and imaginations. Meanwhile, the concept of hallucination came to be used for investigating those experiences of overexcited memories and imaginations that led to failures in judgement or reason.

The second point to highlight is that the mediator view of SLMP was effectively abandoned within experimental uses of each concept by the end of the $20^{\text {th }}$ century. On the one hand, mental imagery went from being required for thought to an unnecessary, and even childish, pastime. While the value of mental imagery as a scientific concept was eventually rehabilitated, SLMP remained merely one of the many forms in which sensory data were thought to be represented in aid of thought. Meanwhile, views on hallucinations had shifted. Rather than being investigated as a dysfunctional form of mental imagery, hallucinations became thought of as a disruption of any number of other "normal" functions - including various perceptual, language, and attentional processes.

Despite being explicitly abandoned, the mediator view of SLMP remains evident in the unresolved tension between the current independent uses of these two concepts and their interdependent histories. In line with the view of Bachelard, Canguilhem, and others, the histories of these concepts provide crucial context for understanding their current uses. In short, while the typical inverse characterization of mental imagery and hallucinations was once philosophically justified, this justification is no longer considered an adequate explanation for the relationship between ordinary and pathological SLMP. Indeed, the typical characteristics used to distinguish between ordinary and abnormal SLMP turn out to be unreliable at best (Smith 2018b: chapter 3). Nonetheless, these characteristics - and the entrenched mediator view associations they emerged within - continue to provide the unacknowledged structure within which the concepts of mental imagery and hallucination are each used as independent concepts for investigating ordinary and pathological SLMP respectively.

scope: I simply seek to highlight that multiple philosophical accounts positioned SLMP as a mediator, of variable value, between unruly bodily perception and the goal of abstract thought. 
Comparing how unexpected findings were accommodated provides a final illustration of the ways in which the associations carried along by each concept (Table 2) contributed to individual experimental practices. In one experiment, an unexpected finding implicated a language brain region with experiences of mental imagery. This finding was taken to suggest that verbal memory is required during the effortful process of generating mental imagery from language cues. In another experiment, there was an unexpected mismatch between the self-reported timing of hallucinations and the timing of localized changes in activity expected in subjects who hallucinate. The unexpectedness of this finding was resolved by dismissing the subject's selfreports; a subject cannot be relied upon to accurately report their experiences anyway. In each case, the disciplined performances of using a given concept (in ways structured by routine associations) provided a pathway for researchers to passively follow (to borrow Pickering's language).

This path of least resistance reduced the need to publicly consider the possibility that an unexpected result might indicate something of interest about either the phenomena under investigation or the tools used to individuate instances of that phenomena. However, to return to an earlier point, these unacknowledged constraints not only shaped the interpretation of such findings but they were also evident in earlier reactive and unjustified methodological choices. In each case, disciplined associations aligned the experimental aims, methods, and results with the specific goal embodied by each concept. During this alignment, investigating SLMP as either mental imagery or hallucinations provided a limited yet flexible array of possible conceptual sequences that could be reached from the emergent interactions within a given experiment.

\section{CONCLUSION}

Drawing on the converging accounts of scientific practice mentioned earlier, I have sought to harness the tension between the current independent uses of two specific concepts (mental imagery and hallucinations) and the unresolved interdependence evident in their intersecting histories. In doing so, I have focused on highlighting the structured associations within which these concepts were each used as tools in individual experiments (where diverging knowledge-claims were generated from equivalent neuroimaging findings).

This point builds on several others that I have touched on in passing: that interdependent concepts can be used as tools for investigating discrete goals, 
that the goal-directed uses of concepts as tools can contribute to experimental practices in analogous ways to material instruments, that the remnants of historical assumptions are carried along by disciplined systems of conceptual associations in ways that remain relevant to the current uses of concepts in generating experimental knowledge, and that these entrenched associations can come to structure the uses of a concept even after the justifications for such associations have been nominally discarded.

While supporting all these claims is beyond the scope of this paper, I hope to have demonstrated the value of examining each of these points in relation to the others. So, to conclude, I have offered a series of examples where the concepts of mental imagery and hallucination were used in ways that relied upon implicit associations - associations grounded by historically contingent structures for how these concepts can be used (in concert with human and material participants) within the temporally dynamic processes of scientific practice. Examining the historical contexts for the disciplined practices that structure the current uses of concepts in this way provides an avenue for understanding the diverging first-order knowledge claims generated from the equivalent findings reported in individual experiments.

With this example, I have sought to highlight how examining the historical development of scientific concepts contributes to our understanding of the structured routines within which these concepts are used as goal-directed tools in experiments. As this example illustrates, there is value in drawing on the converging insights of multiple accounts of scientific practice.

\section{BIBLIOGRAPHY}

Allen P., Larøi F., McGuire P. K., Aleman A. (2008), "The Hallucinating Brain: A Review of Structural and Functional Neuroimaging Studies of Hallucinations," Neuroscience \& Biobehavioral Reviews 32(1), 175-191. https://doi.org/10.1016/j.neubiorev.2007.07.012

Arabatzis T. (2012), "Experimentation and the Meaning of Scientific Concepts" [in:] Scientific Concepts and Investigative Practice, U. Feest, F. Steinle (eds.), Berlin: De Gruyter, 149-166.

Arabatzis T., Nersessian N. J. (2015), “Concepts Out of Theoretical Contexts" [in:] Relocating the History of Science, T. Arabatzis, J. Renn, A. Simões (eds.), Cham: Springer, 225-238. https://doi.org/10.1007/978-3-319-14553-2_15

Badcock J. C., Hugdahl K. (2012), "Examining the Continuum Model of Auditory Hallucinations: A Review of Cognitive Mechanisms" [in:] Hallucinations: Research and Practice, J. D. Blom, I. E. C. Sommer (eds.), New York: Springer, 317-328. https://doi.org/ 10.1007/978-1-4614-0959-5_23 
Bloch C. L. (2012a), "Early Concepts in Investigative Practice the Case of the Virus" [in:] Scientific Concepts and Investigative Practice, U. Feest, F. Steinle (eds.), Berlin: De Gruyter, 191-218.

Bloch C. L. (2012b), Scientific Kinds without Essences [in:] Properties, Powers, and Structures: Issues in the Metaphysics of Realism, A. Bird, B. D. Ellis, H. Sankey (eds.), New York: Routledge, 233-256.

Bloch-Mullins C. L. (2015), "Foundational Questions about Concepts: Context-Sensitivity and Embodiment," Philosophy Compass 10(12), 940-952. https://doi.org/10.1111/ phc3.12272

Boon M. (2012), "Scientific Concepts in the Engineering Sciences: Epistemic Tools for Creating and Intervening with Phenomena" [in:] Scientific Concepts and Investigative Practice, U. Feest, F. Steinle (eds.), Berlin: De Gruyter, 219-244.

Brigandt I. (2010), "The Epistemic Goal of a Concept: Accounting for the Rationality of Semantic Change and Variation," Synthese 177(1), 19-40. https://doi.org/10.1007/ s11229-009-9623-8

Brigandt I. (2012), "The Dynamics of Scientific Concepts" [in:] Scientific Concepts and Investigative Practice, U. Feest, F. Steinle (eds.), Berlin: De Gruyter, 75-103.

Canguilhem G. (2008), Knowledge of Life, P. Marrati, T. Meyers (eds.), trans. S. Geroulanos, D. Ginsburg, 1st ed., New York: Fordham University Press.

Chang H. (2014), "Epistemic Activities and Systems of Practice: Units of Analysis in Philosophy of Science after the Practice Turn" [in:] Science after the Practice Turn in the Philosophy, History, and Social Studies of Science, L. Soler, S. Zwart, M. Lynch, V. Israel-Jost (eds.), Hoboken: Taylor and Francis, 67-79.

Diederen K. M. J., Neggers S. F. W., Daalman K., Blom J. D., Goekoop R., Kahn R. S., Sommer I. E. C. (2010), "Deactivation of the Parahippocampal Gyrus Preceding Auditory Hallucinations in Schizophrenia," American Journal of Psychiatry 167(4), 427435. https://doi.org/10.1176/appi.ajp.2009.09040456

Feest U. (2010), "Concepts as Tools in the Experimental Generation of Knowledge in Cognitive Neuropsychology,” Spontaneous Generations: A Journal for the History and Philosophy of Science 4(1), 173-190. https://doi.org/10.4245/sponge.v4i1.11938

Feest U. (2012), "Exploratory Experiments, Concept Formation, and Theory Construction in Psychology" [in:] Scientific Concepts and Investigative Practice, U. Feest, F. Steinle (eds.), Berlin: De Gruyter, 167-190.

Grossberg S. (2002), "Neural Substrates of Visual Percepts, Imagery, and Hallucinations," Behavioral and Brain Sciences 25(2), 194-195. https://doi.org/10.1017/So140525 X02350040

Gutting G. (1989), Michel Foucault's Archaeology of Scientific Reason, Cambridge-New York: Cambridge University Press.

Haraway D. (2006), "Crittercam: Compounding Eyes in NatureCultures" [in:] Postphenomenology: A Critical Companion to Ihde, E. Selinger (ed.), Albany: State University of New York Press, 175-188.

Hill K., Linden D. E. J. (2013), "Hallucinatory Experiences in Non-clinical Populations" [in:] The Neuroscience of Hallucinations, R. Jardri, A. Cachia, P. Thomas, D. Pins (eds.), New York: Springer, 21-42. https://doi.org/10.1007/978-1-4614-4121-2_2

Hoffman R. E., Hampson M., Wu K., Anderson A. W., Gore J. C., Buchanan R. J., ..., Krystal J. H. (2007), "Probing the Pathophysiology of Auditory/Verbal Hallucinations 
by Combining Functional Magnetic Resonance Imaging and Transcranial Magnetic Stimulation,” Cerebral Cortex 17(11), 2733-2743. https://doi.org/10.1093/cercor/bhl183 Ihde D. (2009), Postphenomenology and Technoscience: The Peking University Lectures, Albany: SUNY Press.

Kindi V. (2012), "Concept as Vessel and Concept as Use" [in:] Scientific Concepts and Investigative Practice, U. Feest, F. Steinle (eds.), Berlin: De Gruyter, 23-46.

Latour B. (2005), Reassembling the Social: An Introduction to Actor-Network-Theory, Chicago: University of Chicago Press.

Law J., Mol A. (2008), "The Actor Enacted: Cumbria Sheep in 2001" [in:] Material Agency: Towards a Non-anthropocentric Approach, C. Knappett, L. Malafouris (eds.), New York-London: Springer, 55-57. https://doi.org/10.1007/978-0-387-74711-8_4

Machery E. (2007), "100 Years of Psychology of Concepts: The Theoretical Notion of Concept and its Operationalization," Studies in History and Philosophy of Science. Part C: Studies in History and Philosophy of Biological and Biomedical Sciences 38(1), 63-84. https://doi.org/10.1016/j.shpsc.2006.12.005

MacLeod M. (2012), "Rethinking Scientific Concepts for Research Contexts: The Case of the Classical Gene" [in:] Scientific Concepts and Investigative Practice, U. Feest, F. Steinle (eds.), Berlin: De Gruyter, 47-74.

Nersessian N. J. (2012), "Modeling Practices in Conceptual Innovation: An Ethnographic Study of a Neural Engineering Research Laboratory" [in:] Scientific Concepts and Investigative Practice, U. Feest, F. Steinle (eds.), Berlin: De Gruyter, 245-270.

Pickering A. (1995), The Mangle of Practice: Time, Agency, and Science, Chicago: University of Chicago Press.

Pickering A. (2006), "Concepts and the Mangle of Practice: Constructing Quaternions" [in:] 18 Unconventional Essays on the Nature of Mathematics, R. Hersh (ed.), New York: Springer, 250-288. https://doi.org/10.1007/0-387-29831-2_15

Pickering A. (2012), "The Robustness of Science and the Dance of Agency" [in:] Characterizing the Robustness of Science After the Practice Turn in Philosophy of Science, L. Soler, E. Trizio, T. Nickles, W. Wimsatt (eds.), Dordrecht: Springer, 17-327. 2759-5_13

Pickering A. (2015), "Science, Contingency, and Ontology" [in:] Science as It Could Have Been, L. Soler, E. Trizio, A. Pickering (eds.), Pittsburgh: University of Pittsburgh Press, 117-128.

Pickering A., Stephanides A. (1992), "Constructing Quaternions: On the Analysis of Conceptual Practice" [in:] Science as Practice and Culture, A. Pickering (ed.), Chicago: University of Chicago Press, 139-167.

Rheinberger H.-J. (2009), "On the Historicity of Scientific Knowledge: Ludwik Fleck, Gaston Bachelard, Edmund Husserl" [in:] Science and the Life-World: Essays on Husserl's Crisis of European Sciences, D. J. Hyder, H.-J. Rheinberger (eds.), Stanford, CA: Stanford University Press.

Rheinberger H.-J. (2010), An Epistemology of the Concrete: Twentieth-Century Histories of Life, Durham, NC: Duke University Press.

Robins R. (2008), "Inventing Oncomice: Making Natural Animal, Research Tool, and Invention Cohere," Genomics, Society, and Policy 4(2), 21-35. https://doi.org/10.1186/ 1746-5354-4-2-21

Rudner M., Rönnberg J., Hugdahl K. (2005), "Reversing Spoken Items - Mind Twisting not Tongue Twisting," Brain and Language 92, 78-90. https://doi.org/10.1016/ j.bandl.2004.05.010 
Schmidgen H. (2014), "The Life of Concepts: Georges Canguilhem and the History of Science," History and Philosophy of the Life Sciences 36(2), 232-253. https://doi.org/ 10.1007/ s40656-014-0030-1

Shine J. M., Keogh R., O’Callaghan C., Muller A. J., Lewis S. J. G., Pearson J. (2015), "Imagine That: Elevated Sensory Strength of Mental Imagery in Individuals with Parkinson's Disease and Visual Hallucinations," Proceedings of the Royal Society B: Biological Sciences 282(1798), 2014-2047. https://doi.org/10.1098/rspb.2014.2047

Smith E. T. (2018a), The Structured Uses of Concepts as Tools: Comparing FMRI Experiments That Investigate Either Mental Imagery or Hallucinations, doctoral thesis, School of Historical and Philosophical Studies, Melbourne: University of Melbourne. MINERVA. http://hdl.handle.net/11343/219955

Smith E. T. (2018b), "Interdependent Concepts and Their Independent Uses: Mental Imagery and Hallucinations," Perspectives on Science 26(3), 360-399. https://doi.org/ $10.1162 /$ posc_a_00278

Steinle F. (2010), "Scientific Facts and Empirical Concepts: The Case of Electricity" [in:] Science as Cultural Practice, M. Epple, C. Zittel (eds.), Berlin: Akademie Verlag, 32-43.

Steinle F. (2012), "Goals and Fates of Concepts: The Case of Magnetic Poles" [in:] Scientific Concepts and Investigative Practice, U. Feest, F. Steinle (eds.), Berlin: De Gruyter, 105-126.

Steinle F. (2016), Exploratory Experiments: Ampere, Faraday, and the Origins of Electrodynamics, trans. A. Levine, Pittsburgh: University of Pittsburgh Press.

Tiles M. (1984), Bachelard, Science, and Objectivity, Cambridge: Cambridge University Press.

Waters C. K. (2014), "Shifting Attention from Theory to Practice in Philosophy of Biology" [in:] New Directions in the Philosophy of Science, M. C. Galavotti, D. Dieks, W. J. Gonzalez, S. Hartmann, T. Uebel, M. Weber (eds.), Cham: Springer, 121-139. https://doi.org/ 10.1007/978-3-319-04382-1_9 